\title{
Optimal dose of intrathecal isobaric bupivacaine in total knee arthroplasty
}

\section{Dose optimale de bupivacaïne intrathécale isobare dans l'arthroplastie totale de genou}

\author{
Jeroen C. van Egmond, MD • Hennie Verburg, MD • Eveline A. Derks, MD • \\ Pim N. J. Langendijk, PharmD • Caner Içli, BSc • Nick T. van Dasselaar, MD, PhD • \\ Nina M. C. Mathijssen, PhD
}

Received: 20 November 2017/Revised: 11 April 2018/Accepted: 18 April 2018/Published online: 1 June 2018

(C) Canadian Anesthesiologists' Society 2018

\begin{abstract}
Purpose Early mobilization is an important aspect of fasttrack protocols and intrathecal bupivacaine is often used in primary total knee arthroplasty (TKA). Although the optimal dose is not known, conventional doses leave patients unable to mobilize for two to four hours. The dose of an intrathecally administered local anesthetic should therefore be optimized to achieve immediate postoperative mobilization. This study determined the median effective dose (ED) of intrathecal bupivacaine for primary unilateral TKA.

Methods Between April 2016 and February 2017 all patients who qualified for unilateral primary TKA were eligible for inclusion. In this dose-finding study, the upand-down method by Dixon and Massey was used, which is a sequential allocation model. Patients received a dose of isobaric bupivacaine according to the outcome of the preceding patient with an initial starting dose of $5 \mathrm{mg}$. The dose was increased or decreased by steps of $0.5 \mathrm{mg}$, depending on the outcome of the preceding patient. During surgery, patients were closely monitored for indications of
\end{abstract}

J. C. van Egmond, MD (凶) · H. Verburg, MD · C. Içli, BSc · N. M. C. Mathijssen, PhD

Department of Orthopedic Surgery, Reinier de Graaf Groep, Reinier de Graafweg 5, 2625 AD Delft, The Netherlands e-mail: j.vanegmond@rdgg.nl

E. A. Derks, MD - N. T. van Dasselaar, MD, PhD

Department of Anesthesiology, Reinier de Graaf Groep, Delft, The Netherlands

P. N. J. Langendijk, PharmD

Department of Pharmacy, Reinier de Graaf Groep, Delft,

The Netherlands pain. Time points of regaining motor and sensory functions were determined.

Results Twenty-five patients were included. Mean (SD) age was 70.1 (8.8) yr old, median [IQR] body mass index was 29.5 [27.3-30.9 $\left.\mathrm{kg} \cdot \mathrm{m}^{-2}\right]$, and $48 \%$ were female. In 11 patients the dose was inadequate; of these, nine patients needed additional anesthesia during surgery, and in four of these nine patients a conversion to general anesthesia was required. The median ED was 3.5 (95\% confidence interval [CI], 3.1 to 4.0) $\mathrm{mg}$ of intrathecal bupivacaine. The calculated ED50 was 3.4 (95\% CI, 2.7 to 4.0) $\mathrm{mg}$; the calculated ED95 was 5 (95\% CI, 3.7 to 8.0) $\mathrm{mg}$.

Conclusion In this small study with tight control over operative duration, the median effective dosage of intrathecal isobaric bupivacaine for primary unilateral TKA was $3.5 \mathrm{mg}$ and the ED95 was $5 \mathrm{mg}$. Reduction of conventional dosages of intrathecal bupivacaine is feasible at centres using fast-track arthroplasty protocols.

\section{Résumé}

Objectif La mobilisation précoce est un élément important des protocoles de réhabilitation accélérée et la bupivacaïne intrathécale est souvent utilisée dans l'arthroplastie totale primaire de genou. Même si on ne connaît pas sa dose optimale, les doses conventionnelles ont pour effet de rendre impossible la mobilisation des patients pendant deux à quatre heures. La dose d'un anesthésique local administré par voie intrathécale doit donc être optimisée pour permettre une mobilisation postopératoire immédiate. Cette étude a établi la dose efficace $(D E)$ médiane de bupivacäne intrathécale pour une arthroplastie totale de genou primaire, unilatérale. Méthodes Tous les patients répondant aux critères d'arthroplastie totale de genou primaire unilatérale entre 
avril 2016 et février 2017 ont été jugés admissibles à l'inclusion dans l'étude. Cette étude de détermination de doses a fait appel à la méthode plus-moins de Dixon et Massey, soit un modèle d'affectation séquentielle. Les patients ont reçu une dose de bupivacä̈ne isobare en fonction des résultats chez le patient précédent avec une dose de départ initiale de $5 \mathrm{mg}$. La dose a été augmentée ou diminuée par paliers de $0,5 \mathrm{mg}$, en fonction des résultats observés chez le patient précédent. Les patients ont été étroitement surveillés pendant l'intervention à la recherche de signes indiquant de la douleur. Les moments de la récupération des fonctions motrices et sensitives ont été consignés.

Résultats Vingt-cinq patients ont été inclus. L'âge moyen (ET) était de 70,1 (8,8) ans, l'indice de masse corporelle médian (EIQ) était de 29,5 (27,3 à 30,9 $\left.\mathrm{kg} \cdot \mathrm{m}^{-2}\right)$ et $48 \%$ étaient des femmes. La dose a été insuffisante chez 11 patients; parmi ces patients, neuf ont nécessité une anesthésie supplémentaire en cours de chirurgie et la conversion en anesthésie générale a été nécessaire pour quatre des neuf patients. La DE médiane était de 3,5 (intervalle de confiance [IC] à $95 \%: 3,1$ à 4,0) $m g$ de bupivacaïne intrathécale. La DE50 calculée était de 3,4 (IC à $95 \%$ : 2,7 à 4,0) mg; la DE95 calculée était de 5 (IC à $95 \%: 3,7$ à 8,0) $m g$

Conclusion Dans cette petite étude avec contrôle strict de la durée de l'intervention chirurgicale, la dose efficace médiane de bupivacaïne intrathécale isobare pour arthroplastie totale de genou primaire unilatérale a été de 3,5 mg avec une DE95 de $5 \mathrm{mg}$. La diminution des doses conventionnelles de bupivacaïne intrathécale est faisable dans les centres utilisant des protocoles de réhabilitation accélérée d'arthroplastie.

During the last decades, fast-track protocols have been introduced for total knee arthroplasty (TKA), which have reduced the length of hospital stay without an increase of complications and readmissions. ${ }^{1,2}$ Early mobilization is an important aspect of these fast-track protocols. ${ }^{3}$ Therefore, they create new challenges in anesthesia protocols requiring dose optimization to allow immediate postoperative mobilization.,

In fast-track TKA, intrathecal anesthesia is preferred over general anesthesia because of lower mortality and morbidity rates. ${ }^{6-9}$ Moreover, spinal anesthesia yields lower postoperative pain scores and less nausea and vomiting after TKA. ${ }^{10,11}$

Current dosages of intrathecal bupivacaine interfere with immediate postoperative mobilization and often leave patients unable to mobilize for two to four hours after surgery, which prolongs hospital stay. ${ }^{3}$ Awad et al. found significantly earlier recovery room discharge after TKA with low-dose $(5 \mathrm{mg})$ isobaric bupivacaine in combination with a femoral and sciatic nerve block compared with their standard 10-mg dosage. ${ }^{12}$

We presume it might be feasible to reduce the dosage of bupivacaine to optimize the rehabilitation after primary TKA.

\section{Methods}

The study was approved by the Institutional Review Board METCZWH (HagaZiekenhuis, Den Haag, the Netherlands, March 2016) and was registered in EudraCT (2016000082-23). All included patients gave their written informed consent before enrolment.

Patients

All consecutive patients between April 2016 and February 2017 who qualified for unilateral primary TKA at Reinier de Graaf Hospital (Delft, the Netherlands) were eligible for inclusion. Inclusion criteria were: American Society of Anesthesiologists physical status I, II, or III physical status, sufficient command of the Dutch language, willingness to participate, and being competent to decide.

Patients were excluded in cases of hypersensitivity to local anesthetics or any of the other excipients of bupivacaine and in cases with contraindications to intrathecal anesthesia. All patients were operated on by a single orthopedic surgeon (H.V.) and the same anteromedial approach and prosthesis (NexGen ${ }^{\circledR}$ LPSHigh Flex Fixed Bearing Knee prosthesis; Zimmer®, Warsaw, IN, USA) was used in all patients. A tourniquet was not used on any of the patients during surgery.

\section{Measurements}

The primary outcome of this present study was the median effective dose (ED) of isobaric bupivacaine in primary TKA to allow immediate postoperative mobilization as well as adequate anesthesia during surgery. The up-anddown method as described by Dixon and Massey was used. $^{13,14}$ This is a sequential allocation model in which patients received a dose of isobaric bupivacaine according to the outcome of the preceding patient. A starting dose of the test sequence was set to $5 \mathrm{mg}$ bupivacaine.

According to Gautier et al. intrathecal administration of $8 \mathrm{mg}$ bupivacaine at level L3-4 will lead to a motor blockade of 100-225 min and a sensory blockade of 90-190 min. ${ }^{15}$ Nevertheless, the mean surgery time for TKA is 
shorter; a duration (standard deviation, SD) of 83 (18) min was described by Lozano et al. ${ }^{16}$

To determine the dose of bupivacaine adequate for most patients, a threshold at the 95th percentile of mean surgery time for TKA was defined from our surgery statistics. In 2015, the mean duration of primary TKA surgery was 71 min at our institution. Nevertheless, surgery times ranged between 45 and $144 \mathrm{~min}$. The 95th percentile of mean surgery time was $101 \mathrm{~min}$. According to the Summary of Product Characteristics, the mean onset time of the sensory blockade is $15 \mathrm{~min}$. This time was added to the mean surgery time; therefore, a threshold at $116 \mathrm{~min}$ after injecting intrathecal anesthesia was used. When no sensory blockage was reached within 15 min after administration, the start of surgery was postponed.

An adequate dose (no pain during surgery and regaining motor and sensory functions after $116 \mathrm{~min}$ ) led to a decrease of $0.5 \mathrm{mg}$ bupivacaine and an inadequate dose (pain during surgery) led to a $0.5 \mathrm{mg}$ increase of bupivacaine for the subsequent patient (Fig. 1).

To test the diminution of spinal blockade, patients received repetitive questions and tests with ten-minute intervals regarding sensory and motor functions from start of surgery (Fig. 2). During surgery, the heart rate and blood pressure were monitored to determine if the patient was in pain; since patients received propofol infusion to induce light sedation some were not always able to answer questions regarding pain during surgery. No pre-defined limits of heart rate or blood pressure were used. Changes in one or both were judged by the anaesthesiologist and he/ she decided if the patient was in pain. Postoperatively, a pinprick test was performed by a trained investigator at dermatome L5 and S1 to test regained sensory functions. A small sharp wooden stick was used to prick the skin at the dorsum of both feet and the patient was asked if he/she experienced this as a sharp sensation. Moreover, the modified Bromage scale (grade $0=$ no weakness; grade 1 $=$ inability to raise extended leg; grade $2=$ inability to flex knee; grade $3=$ inability to move any joint in legs) was used to test motor functions. ${ }^{17}$ If patients reached full recovery of the motor blockade (Bromage grade 0) and full recovery of the sensory blockade (positive pinprick test at S1 dermatome) after the threshold of $116 \mathrm{~min}$ after administration of anesthesia, the dose was adequate.

The single surgeon and his assistant, the patient, and the investigator (who performed the per- and postoperative tests) were all blinded to the used dosage of bupivacaine. Based on the outcome of the preceding patient, the dosage of the subsequent patient was determined by one of the researchers (N.M.) who only informed the anesthesiologist of the dose to be administered.
Anesthesia

All patients were admitted on the day of surgery. At admission, participants received $400 \mathrm{mg}$ celecoxib, $1 \mathrm{~g}$ of paracetamol, and $600 \mathrm{mg}$ of gabapentin on the ward. Furthermore, in the preoperative holding area, patients received dexamethasone $0.15 \mathrm{mg} \cdot \mathrm{kg}^{-1} i v^{18,19}$ as well as antibiotic prophylaxis; $0.5 \%$ isobaric bupivacaine (Marcaine ${ }^{\circledR}$ spinal $5 \mathrm{mg} \cdot \mathrm{mL}^{-1}$; Aspen, Gorinchem, the Netherlands) was administered intrathecally at the L2-L3 or L3-L4 intervertebral space by an experienced anesthesiologist. The spinal block was performed in a dedicated block room. The patient was in a sitting position when the bupivacaine was administered and was put in supine position two minutes after injecting isobaric bupivacaine. Cerebrospinal fluid was aspirated before and after injection. Opiates were not administered to rule out possible side effects such as nausea, vomiting, or sedation, which might prolong the length of stay after surgery. ${ }^{20,21}$

All included patients received standard additional local infiltration anesthesia with $300 \mathrm{mg}$ ropivacaine and $3 \mathrm{mg}$ epinephrine around the knee joint during the end of surgery, conforming to our fast-track regimen. Propofol was continually administered for sedation and to allow a single shot of $15 \mathrm{mg}$ esketamine $i v$ without unwanted side effects. Esketamine was administered to prevent postoperative pain. ${ }^{22,23}$ Propofol was given by targetcontrolled infusion (TCI), which is often used in anesthesia to control the concentration of selected drugs in the plasma or at the site of its effect. In our protocol, patients received propofol 1-2 $\mu \mathrm{g} \cdot \mathrm{mL}^{-1}$ set as target concentration administered through a TCI Diprifusor ${ }^{\mathrm{TM}}$ pump (Carefusion, Basingstoke, UK) using the Marsh model. ${ }^{24}$

If a patient showed signs of insufficient anesthesia during surgery, he/she received general anesthesia; the patient was then treated with propofol, remifentanil, and a laryngeal mask.

\section{Statistical analysis}

At least six independent pairs of patients with sufficient/ insufficient anesthesia should provide reliable estimates of median ED using the up-and-down method by Dixon and Massey. ${ }^{25}$ A group of 20 to 30 patients was sufficient to have six independent pairs of patients with response/no response. Therefore, a sample size of 25 patients was chosen for this study. Dixon and Massey's method was used to calculate the median ED with the $95 \%$ confidence interval (CI). ${ }^{13,14}$ The average of the dose of the "fail/success" pair was chosen. The data were further analyzed; the ED50 and ED95 were calculated by the MASS package. ${ }^{26}$ With the BOOT package, 1,000 bootstrap resamples were generated to determine the CI 
of the ED50 and ED95. ${ }^{27}$ For statistical analysis, IBM SPSS statistics for Windows version 21 (IBM SPSS, Armonk, NY, USA) and R for Windows version 3.2.4 Revised (R Foundation for Statistical Computing, Vienna, Austria) were used.

\section{Results}

Between April 2016 and February 2017, a total of 118 patients were eligible for inclusion. Twenty-five patients were included. Thirty-five patients were excluded because of contraindications to intrathecal anesthesia (anticoagulant use, spinal herniation/stenosis), eight patients were excluded for logistical reasons, five patients were excluded because of expected prolonged surgery time because of removal of plate osteosynthesis of previously performed osteotomy, and 45 patients were not willing to participate (Fig. 3).

The mean (SD) age of the included patients was 70.1 (8.8) yr old, $12(48 \%)$ patients were female, and in 15 patients $(60 \%)$ the left knee was operated on. The mean (SD) height was 174 (9) $\mathrm{cm}$ [range, 158-191] and the median [interquartile range (IQR)] body mass index (BMI) was 29.5 [27.3 - 30.9] (Table 1).

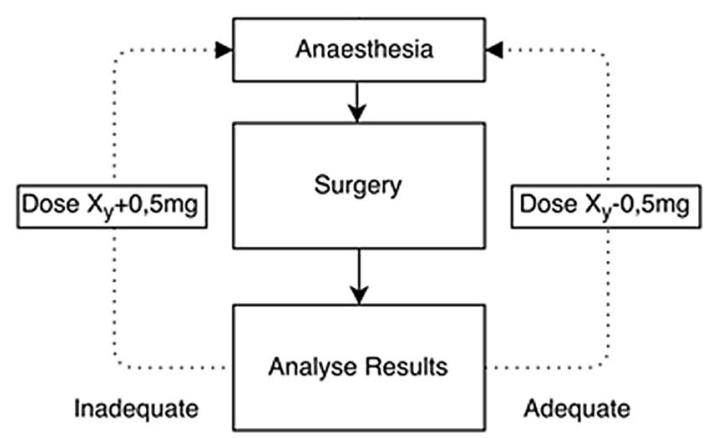

Fig. 1 Dose determination chart based on the up-and-down method by Dixon and Massey. Adequate = no pain during surgery, regaining motor and sensory functions after $116 \mathrm{~min}$. Inadequate $=$ patients were in pain during surgery

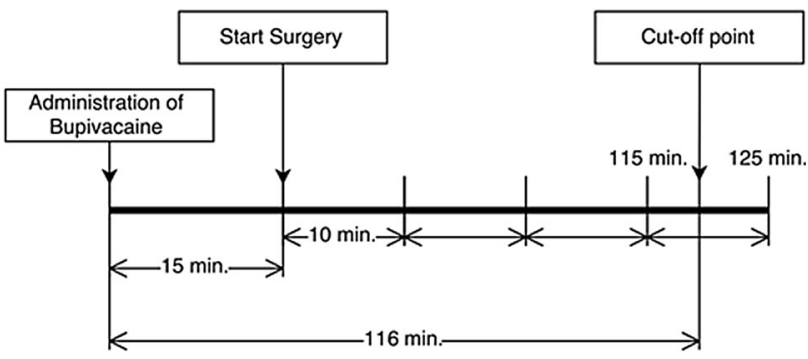

Fig. 2 Test interval time frame. Cut-off point is the predefined threshold of 116 min after administrating intrathecal anesthesia
Doses varied between $5.0 \mathrm{mg}$ and $2.5 \mathrm{mg}$ of bupivacaine. In 11 patients the dose was inadequate and the subsequent patient received an increased dose. Of these 11 patients, nine required additional intravenous analgesia and four of the nine patients also required a conversion to general anesthesia. The mean (SD) duration of sensory blockade in the total group was 118 (45) min. The mean (SD) motor blockade was 111 (24) $\mathrm{min}$ in all patients without general anesthesia ( $n=21$; Table 2$)$. In all patients with sufficient intrathecal anesthesia during surgery, motor function was regained prior to sensory function.

The data sequence of adequate and inadequate doses is shown in Fig. 4. The median dose of bupivacaine resulting in adequate analgesic blockade at the threshold of $116 \mathrm{~min}$ was $3.5 \mathrm{mg}$ (95\% CI, 3.1 to 4.0). The ED50 and ED95 were, respectively, 3.4 (95\% CI, 2.7 to 4.0 ) $\mathrm{mg}$ and 5.0 (95\% CI, 3.7 to 8.0 ) $\mathrm{mg}$.

\section{Discussion}

The goal of this dose-finding study was to determine the median ED of intrathecal bupivacaine that preserved adequate anesthesia during surgery. The outcome of this study might validate adjustments to the current anesthesia protocols, which might further optimize fast-track protocols.

The median ED in our study was 3.5 (95\% CI, 3.1 to 4.0) $\mathrm{mg}$ bupivacaine, which is much less compared with the amount normally given in our hospital $(6-8 \mathrm{mg})$ and the amounts of bupivacaine used in many previous studies. For example, the recent study of Harsten et al., which compared general anesthesia with spinal anesthesia for TKA, $15 \mathrm{mg}$ bupivacaine was administered. ${ }^{28}$ This study showed an overall favourable outcome for general anesthesia; however, no optimal dose of bupivacaine was used. Lowering the dosage could change the immediate postoperative outcomes in favour of spinal anesthesia. ${ }^{29}$

In the study of Awad et al. patients were randomized to $5 \mathrm{mg}$ or $10 \mathrm{mg}$ intrathecal bupivacaine in combination with a femoral and sciatic nerve block, and they found earlier postanesthesia care unit discharge and fewer voiding problems in the 5-mg group. In our study, voiding was not examined; therefore, no urine retention tests were presented. Based on the findings of Awad et al., lower doses of bupivacaine reduce the risk of urine retention. This needs to be examined in new studies. ${ }^{12}$

The results of our study are consistent with the recent study by Mathijssen et al. (unpublished data), which examined the median effective dose of bupivacaine in total hip arthroplasty (THA). In this study a median dose of 5.7 $\mathrm{mg}$ (95\% CI 5.2 to 6.1) bupivacaine was sufficient for 


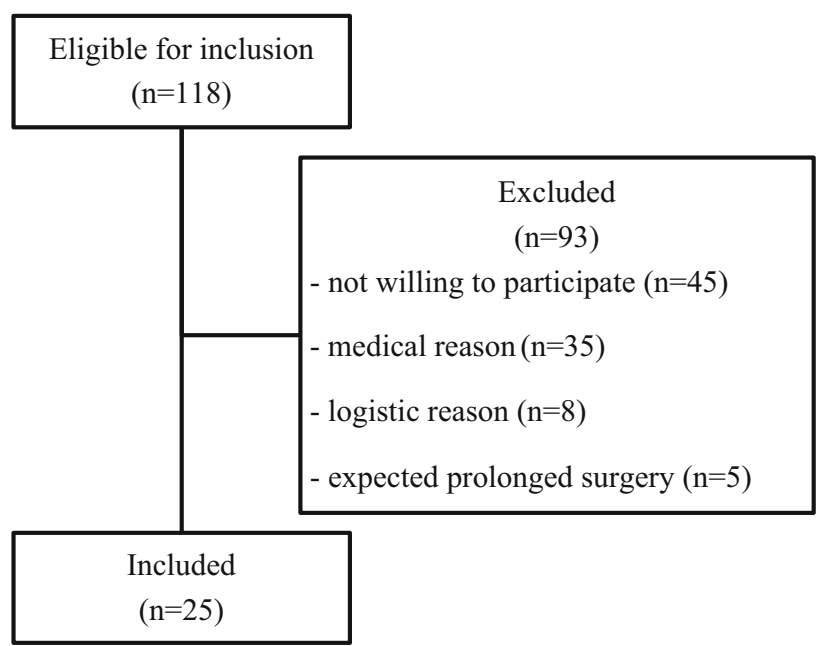

Fig. 3 Flowchart of patients

adequate anesthesia during primary unilateral THA surgery and allowed immediate postoperative mobilization.

No dose adjustments were made for bodyweight or height since no hard evidence has been found that this influences spinal anesthesia outcomes. One study has described that the duration of spinal blockade in obese patients appears to be prolonged. ${ }^{30}$ Even though our patient group contained a wide variation of BMIs, we presume this had no influence on our outcomes. Moreover, of the 11 patients in whom the dosage was insufficient and the four patients who needed general anesthesia, the mean BMI was equal to that of the sufficient group (however, these numbers are small).

No dose adjustments were made for age, although age might affect motor blockade duration in which older patients requires less bupivacaine. ${ }^{31}$ Since the mean age of our study population was not extensively spread and representative for the national age for TKA as found by the
Dutch arthroplasty register, no subdivision based on age was made and the outcome was analyzed as one group. ${ }^{32}$

The predefined dose of bupivacaine was not diluted to maintain baricity. Various studies have shown that dosage is a more important factor than volume and concentration of local anesthetics when administered intrathecally and volume does not influence the maximal spread or sensory or motor blockade. ${ }^{33,34}$

There are some limitations of this study that need to be addressed.

First, we did not determine the exact moment of recurring motor and sensory functions. As practiced by other studies, a ten-minute interval for testing pinprick sensation is adequate to assess regained sensory functions. ${ }^{35,36}$ Bhat et al. have shown that a ten-minute interval for the assessment of motor functions with the Bromage scale can be used. ${ }^{37}$

Second, the results of this study can only be used for primary unilateral TKA, since the dosage is determined on a threshold of the 95th percentile surgery time of primary unilateral TKA in a large teaching hospital. In complicated cases, revisions, or bilateral TKA, dose adjustments may be necessary.

Third, a substantial number of patients were excluded or refused to participate in this study (Fig. 3). Patients refused to contribute for various reasons, mostly because of fear of pain during surgery. A significant number of patients were excluded from intrathecal anesthesia because of anticoagulant medication, which was an exclusion criterion in this study. Although a substantial number of the eligible patients were excluded, we expected no bias since we included a representative patient group.

Fourth, no postoperative pain scores were reported. Moreover, no time to first postoperative mobilization was registered. Therefore, the clinical implications of our study are somewhat uncertain. Now that we have presented that

Table 1 Patient characteristics

\begin{tabular}{lll}
\hline & $n=25$ & 25th-75th percentile \\
\hline Age, yr & $70.1(8.8)$ & \\
Gender, female & $12(48 \%)$ & \\
Side, left & $15(60 \%)$ & \\
Length, cm & $174(9)$ & $27.3-30.9$ \\
BMI kg.m ${ }^{-2}[$ median] & 29.5 & \\
ASA I & $4(16 \%)$ & \\
II & $17(68 \%)$ & \\
III & $4(16 \%)$ & \\
\hline
\end{tabular}

All values are presented as mean (standard deviation) or as $n(\%)$. BMI was not normally distributed; therefore, the 25 th and 75 th percentiles are presented

ASA = American Society of Anesthesiologists; BMI = body mass index 
Table 2 Mean duration of blockade (minutes)

\begin{tabular}{lll}
\hline & Total & Without additional anesthesia \\
\hline Motor blockade & $111(24)$ & $115(17)$ \\
& $(n=21)$ & $(n=16)$ \\
Sensory blockade & $118(45)$ & $141(25)$ \\
& $(n=25)$ & $(n=16)$ \\
\hline
\end{tabular}

All values are mean (standard deviation)

Missing cases: no further motor blockade tests were performed after general anesthesia

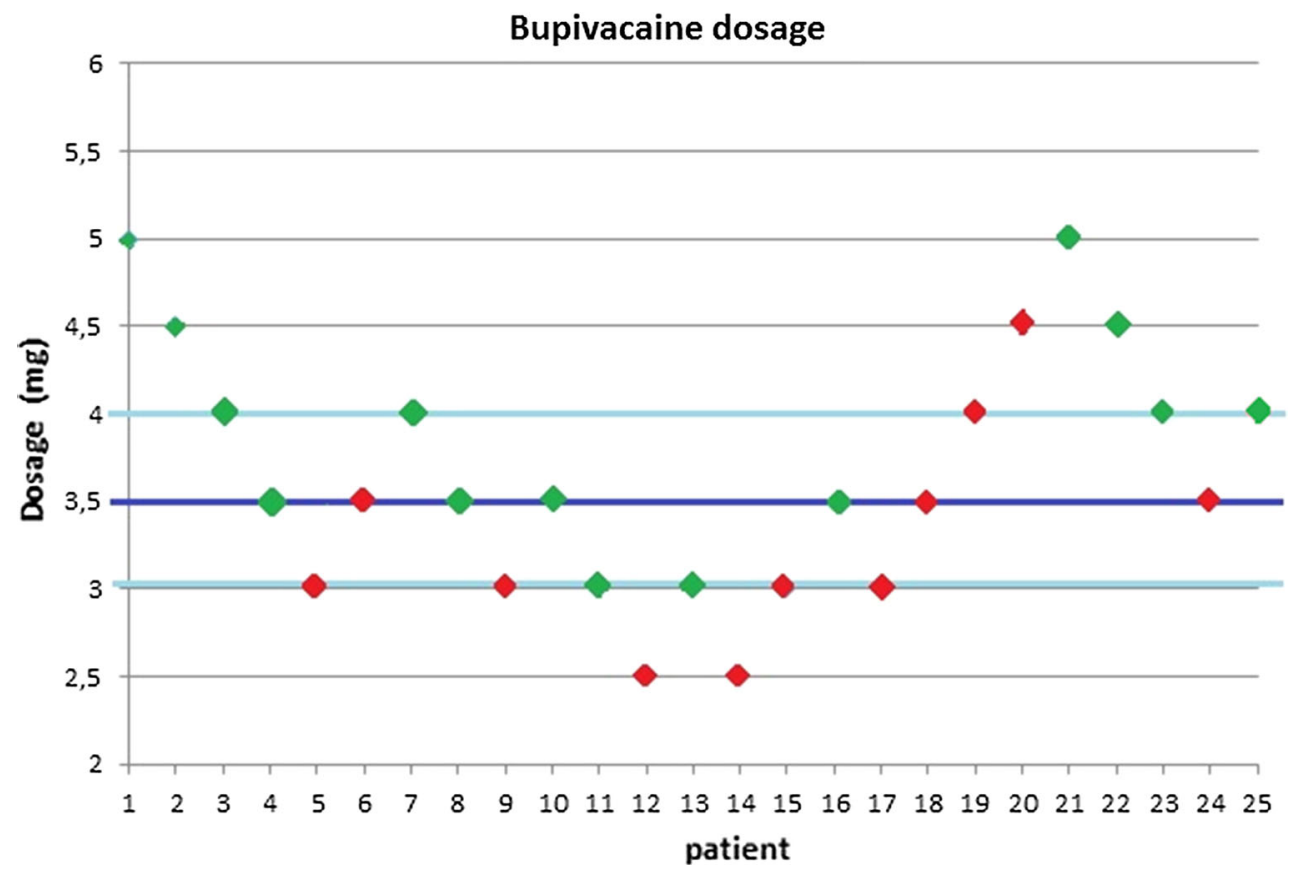

Fig. 4 Graphic of bupivacaine dosage during the study; each rhomb equals a patient. Green rhomb = adequate dosage; red rhomb = inadequate dosage

lower dosages of bupivacaine are feasible, further studies are needed to determine the clinical effects on time to postoperative mobilization, incidence of urine retention, pain scores, and length of hospital stay. This is particularly true in teaching hospitals, where the duration of surgery can be highly variable.

Finally, no direct estimation of the ED95 can be made using the up-and-down method of Dixon and Massey. Therefore, the ED95 was calculated rather than directly observed.

In conclusion, the current dose of $10 \mathrm{mg}$ of bupivacaine in primary TKA can be reduced. Using a lower dose of intrathecal isobaric bupivacaine is feasible in primary, well-planned unilateral TKA in conjunction with a preoperative multimodal analgesic regimen and perioperative sedation using propofol. For patients who are not good candidates for propofol, the intraoperative course might be quite different. The lower dosage of bupivacaine provided sufficient anesthesia in many patients, but the procedures had to be well planned regarding logistics and time management. In this small study with tight control over operative duration, the median effective dosage of intrathecal isobaric bupivacaine for primary unilateral TKA was $3.5 \mathrm{mg}$ (95\% CI, 3.1 to 4.0 ); the calculated ED95 was $5 \mathrm{mg}$ (95\% CI, 3.7 to 8.0$)$.

The results of this present study might lead to the justification of lower doses of bupivacaine for intrathecal anesthesia in primary TKA. Consequently, the fast-track program can be further optimized.

Acknowledgement The authors thank all the patients as well as Nicole de Esch, Yvonne van Limburg, and Brechtje Hesseling, MSc., of the Orthopedic Department at the Reinier the Graaf Groep, Delft, the Netherlands, for their help with including patients for this study. 
Conflicts of interest None declared.

Editorial responsibility This submission was handled by Dr. Philip M. Jones, Associate Editor, Canadian Journal of Anesthesia.

Author contributions Jeroen C. van Egmond performed the data analysis and perioperative measurements and wrote and revised the manuscript. Hennie Verburg operated all of the included patients, designed the study, and critically reviewed the manuscript. Eveline A. Derks performed the spinal anesthesia in all patients and critically reviewed the manuscript. Pim N.J. Langendijk designed the study and critically reviewed the manuscript. Caner Içli performed most of the perioperative measurements and critically reviewed the manuscript. Nick T. van Dasselaar designed the study and critically reviewed the manuscript. Nina M.C. Mathijssen designed the study, supported data analysis, determined dosages, and critically reviewed the manuscript. All authors approved the final version of the manuscript.

Financial disclosures None.

\section{References}

1. Dowsey MM, Kilgour ML, Santamaria NM, Choong PF. Clinical pathways in hip and knee arthroplasty: a prospective randomised controlled study. Med J Aust 1999; 170: 59-62.

2. Barbieri A, Vanhaecht K, Van Herck P, et al. Effects of clinical pathways in the joint replacement: a meta-analysis. BMC Med 2009; 7: 32.

3. Husted H, Hansen HC, Holm G, et al. What determines length of stay after total hip and knee arthroplasty? A nationwide study in Denmark. Arch Orthop Trauma Surg 2010; 130: 263-8.

4. Tarkkila $P$, Huhtala J, Tuominen M. Home-readiness after spinal anaesthesia with small doses of hyperbaric $0.5 \%$ bupivacaine. Anaesthesia 1997; 52: 1157-60.

5. Turnbull ZA, Sastow D, Giambrone GP, Tedore T. Anesthesia for the patient undergoing total knee replacement: current status and future prospects. Local Reg Anesth 2017; 10: 1-7.

6. Pugely AJ, Martin CT, Gao Y, Mendoza-Lattes S, Callaghan JJ. Differences in short-term complications between spinal and general anesthesia for primary total knee arthroplasty. J Bone Joint Surg Am 2013; 95: 193-9.

7. Basques BA, Toy JO, Bohl DD, Golinvaux NS, Grauer JN. General compared with spinal anesthesia for total hip arthroplasty. J Bone Joint Surg Am 2015; 97: 455-61.

8. Wong PB, McVicar J, Nelligan K, Bleackley JC, McCartney CJ. Factors influencing the choice of anesthetic technique for primary hip and knee arthroplasty. Pain Manag 2016; 6: 297-311.

9. Memtsoudis SG, Sun X, Chiu YL, et al. Perioperative comparative effectiveness of anesthetic technique in orthopedic patients. Anesthesiology 2013; 118: 1046-58.

10. Gonano C, Leitgeb U, Sitzwohl C, Ihra G, Weinstabl C, Kettner $S C$. Spinal versus general anesthesia for orthopedic surgery: anesthesia drug and supply costs. Anesth Analg 2006; 102: 524-9.

11. Sansonnens J, Taffe P, ADS Study Group. Higher occurrence of nausea and vomiting after total hip arthroplasty using general versus spinal anesthesia: an observational study. BMC Anesthesiol 2016; 16: 44.

12. Awad IT, Cheung JJ, Al-Allaq Y, Conroy PH, McCartney CJ. Low-dose spinal bupivacaine for total knee arthroplasty facilitates recovery room discharge: a randomized controlled trial. Can J Anesth 2013; 60: 259-65.
13. Dixon WJ, Massey FJ Jr. Introduction to Statistical Analysis. NY: McGraw-Hill; 1969. p. 344

14. De Jonge H. Inleiding tot de Medische Statistiek II - Klassieke Methoden. Verhandeling van het Nederlands Instituut voor Praeventieve Geneeskunde XLVIII; 1960. Available from URL: https://publications.tno.nl/publication/34610624/gx31hc/jonge1960-klassieke.pdf (accessed April 2018).

15. Gautier P, De Kock M, Huberty L, Demir T, Izydorczic M, Vanderick $B$. Comparison of the effects of intrathecal ropivacaine, levobupivacaine, and bupivacaine for caesarean section. Br J Anaesth 2003; 91: 684-9.

16. Lozano LM, Tio M, Rios J, et al. Severe and morbid obesity (BMI $\geq 35 \mathrm{~kg} / \mathrm{m}(2))$ does not increase surgical time and length of hospital stay in total knee arthroplasty surgery. Knee Surg Sports Traumatol Arthrosc 2015; 23: 1713-9.

17. Bromage $P R$. A comparison of the hydrochloride and carbon dioxide salts of lidocaine and prilocaine in epidural analgesia. Acta Anaesthesiol Scand Suppl 1965; 16: 55-69.

18. De Oliveira GS, Jr Almeida MD, Benzon HT, McCarthy RJ. Perioperative single dose systemic dexamethasone for postoperative pain: a meta-analysis of randomized controlled trials. Anesthesiology 2011; 115: 575-88.

19. Lunn TH, Andersen LO, Kristensen BB, et al. Effect of high-dose preoperative methylprednisolone on recovery after total hip arthroplasty: a randomized, double-blind, placebo-controlled trial. Br J Anaesth 2013; 110: 66-73.

20. Husted H, Lunn TH, Troelsen A, Gaarn-Larsen L, Kristensen BB, Kehlet $H$. Why still in hospital after fast-track hip and knee arthroplasty? Acta Orthop 2011; 82: 679-84.

21. Jia XF, Ji Y, Huang GP, Zhou Y, Long M. Comparison of intrathecal and local infiltration analgesia by morphine for pain management in total knee and hip arthroplasty: a meta-analysis of randomized controlled trial. Int J Surg 2017; 40: 97-108.

22. Adam F, Chauvin M, Du Manoir B, Langlois M, Sessler DI, Fletcher $D$. Small-dose ketamine infusion improves postoperative analgesia and rehabilitation after total knee arthroplasty. Anesth Analg 2005; 100: 475-80.

23. Remerand $F$, Le Tendre $C$, Baud A, et al. The early and delayed analgesic effects of ketamine after total hip arthroplasty: a prospective, randomized, controlled, double-blind study. Anesth Analg 2009; 109: 1963-71.

24. Marsh B, White M, Morton N, Kenny GN. Pharmacokinetic model driven infusion of propofol in children. Br J Anaesth 1991; 67: 41-8.

25. Dixon WJ. The Up-and-Down method for small samples. J Am Stat Assoc 2012; 60: 967-78.

26. Venables WN, Ripley BD. Modern applied Statistics with S. 4th ed. NY: Springer; 2002.

27. Davison AC, Hinkley DV. Bootstrap Methods and their Applications. Cambridge: Cambridge University Press; 1997.

28. Harsten A, Kehlet $H$, Ljung $P$, Toksvig-Larsen $S$. Total intravenous general anaesthesia vs. spinal anaesthesia for total hip arthroplasty: a randomised, controlled trial. Acta Anaesthesiol Scand 2015; 59: 298-309.

29. Hansen TB. Fast track in hip arthroplasty. EFORT Open Rev 2017; 2: 179-88.

30. Kim HJ, Kim WH, Lim HW, et al. Obesity is independently associated with spinal anesthesia outcomes: a prospective observational study. PloS ONE 2015; 10: e0124264.

31. Chen $M$, Chen $C, K e Q$. The effect of age on the median effective dose (ED50) of intrathecally administered plain bupivacaine for motor block. Anesth Analg 2014; 118: 863-8.

32. LROI-Rapportage. Orthopedische Implantaten in Beeld. 2014. Available from URL: https://www.lroi.nl/base/downloads/lroijaarrapportage-2014.pdf (accessed April 2018). 
33. Bengtsson M, Malmqvist LA, Edstrom HH. Spinal analgesia with glucose-free bupivacaine-effects of volume and concentration. Acta Anaesthesiol Scand 1984; 28: 583-6.

34. Sheskey MC, Rocco AG, Bizzarri-Schmid M, Francis DM, Edstrom H, Covino BG. A dose-response study of bupivacaine for spinal anesthesia. Anesth Analg 1983; 62: 931-5.

35. Malinovsky JM, Renaud $G$, Le Corre $P$, et al. Intrathecal bupivacaine in humans: influence of volume and baricity of solutions. Anesthesiology 1999; 91: 1260-6.
36. Liu S, Kopacz DJ, Carpenter RL. Quantitative assessment of differential sensory nerve block after lidocaine spinal anesthesia. Anesthesiology 1995; 82: 60-3.

37. Bhat SN, Himaldev MU. Comparison of efficacy and safety of ropivacaine with bupivacaine for intrathecal anesthesia for lower abdominal and lower limb surgeries. Anesth Essays Res 2013; 7 : $381-5$. 